\title{
Ecology and mining industry development in high-mountain areas (the Inner Tien Shan)
}

\author{
Yurii Aleshin ${ }^{1 *}$, Ilgiz Aitmatov ${ }^{1}$, Isakbek Torgoev ${ }^{1}$, and Bektur Chukin ${ }^{1}$ \\ ${ }^{1}$ National Academy of Sciences, Institute of Geomechanics and subsoil development, 720055 \\ Bishkek, Kyrgyz Republic
}

\begin{abstract}
The genesis and transformation in time of risks in the areas of high altitude tailings storage facilities with respect to changing climate are considered. Based on the example of the Kumtor mine in the center of the Tien Shan at a height of 3600-4300 m, three groups of risk factors were allocated concerning a large, ecologically hazardous facility - the tailings dam containing cyanide waste. For one of the factors, calculations of an accidental dam burst were made using the Fault Tree Analysis (FTA) method. It was concluded that the construction of large-scaled and geoenvironmentally hazardous facilities in less researched high-mountain areas has to be be drawn upon detailed and permanent monitoring of the facility itself and its environment. It is crucial to be prepared for operational adjustment of projects and an immediate rehabilitation of constructed facilities.
\end{abstract}

\section{Introduction}

Due to the displacement of the mineral resource base of the Kyrgyzstan's mining industry from the foothill and mountainous areas to the highlands in recent years, the conditions for the development of deposits have become significantly more complicated and new problems concerning the ensurance of industrial and environmental safety have arisen. This applies in particular to the gold deposits of Kumtor and Jeruy, located in remote, highmountain areas of the Tien Shan (the absolute height of mining facilities is 3600-4300 m). Distinctive features of the alpine subsurface development are a severe, sharply continental climate, the permafrost state of rocks and a wide development of complex, modern geocryological and glacial processes, the presence of glaciers, snowfields, and icing [1].

Current trends in climate change, combined with high mining pressure on the weakly stable natural environment of the highlands, lead to the degradation of permafrost areas, the retreat of glaciers, the development of destructive processes in soils and the destabilization of natural and man-made objects, including ecologically hazardous tailings storage facilities (TSF). Up to the present day, sufficient experience and adequate factual data, making it possible to form a reliable forecast for long-term interaction of hydraulic structures with the natural geological environment of the highlands and describe the dynamics of risks at the forecast horizon in decades, have not been accumulated. Therefore, the generalization of operation results of such facilities during the first 15 years and the resulting geo-ecological

${ }^{1}$ Correspondent author: geofizika@list.ru 
problems makes it possible to completely identify the complexes of natural and man-made hazards and risks that must be taken into account when choosing the location of their construction.

\section{Overview of the facility and risk factors}

The tailing pond of the Kumtor operating mine is the largest hydrotechnical structure of the Inner Tien Shan permafrost zone: in the next two years the cumulative volume of solid waste storage will reach 65 million $\mathrm{m}^{3}$, the height of the retaining dike is appx. $47 \mathrm{~m}$ and the ridge is more than $4 \mathrm{~km}$ long. It lies in the valley of the Arabel River upstream to its confluence with the Kumtor River, which is the source of the Naryn River (the principal tributary to the Syr Darya River), in close proximity (about $5 \mathrm{~km}$ ) from the proglacial Petrov Lake (Figure 1) within the transit zone of fluvioglacial and mud-flow masses in the Holocene epoch, which cut through the Middle Quaternary moraines. When choosing the location of the tailings pond in 1995, economic considerations, related to the small distance between the gold extraction factory and tailings pond $(6-8 \mathrm{~km})$ and the appropriate morphology of the basin, undoubtedly prevailed.

The practice of subsequent operation of the facility, detailed monitoring of the dam's condition, engineering-geological and geophysical research at the site revealed a number of factors (circumstances and processes) that could lead to the destruction of the facility with catastrophic environmental consequences. Conventionally, there are three groups of risk factors: (1) - internal physical and geological factors in the base and body of the dam,

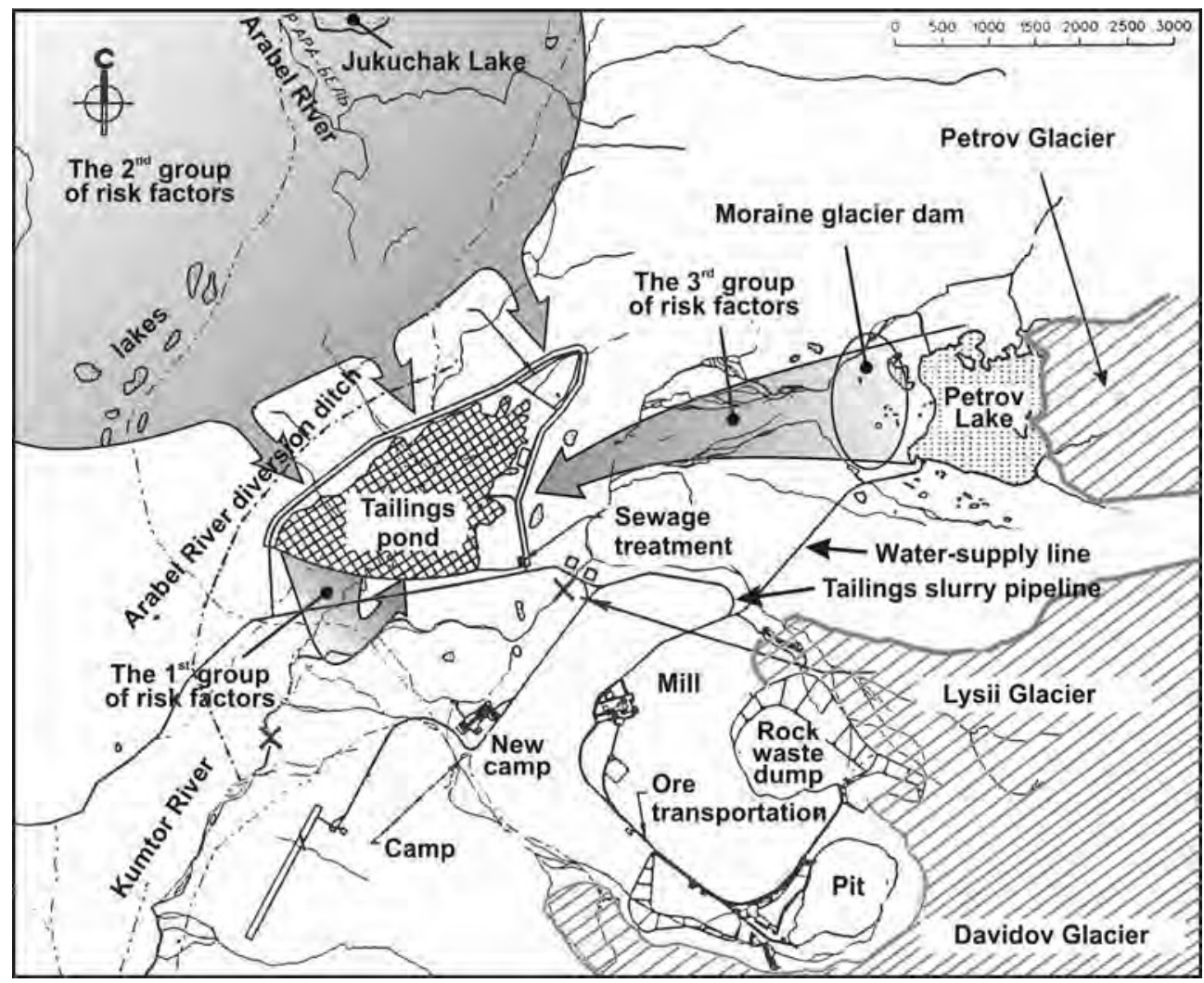

Fig. 1. The groups of risk factors 
leading to a loss of its stability; (2) - hydrogeological and hydrological factors within the catchment area; (3) - glaciological and thermodynamic processes in the structures of the moraine and glacial complex of the Petrov Glacier.

The genesis of the hazards from the first group is determined by the peculiarities of the composition, structure, properties, and thermal regime of the alluvial terrace soils on the border with lacustrine loamy silt deposits of low thickness (up to 2 meters) with a gentle slope (1 to 2 degrees) towards downstream at a depth of approximately 4 meters. These deposits with thin lenses and layers of ice have very low strength characteristics (according to the data of [2], their friction angle is between 1.5 and 2.5 degrees). They had been frozen at the beginning of development, but melted during the facility construction and became the cause of the evolution of large deformations and displacements on the dam-base interface at a velocity of up to $6 \mathrm{~mm} / \mathrm{month}$. The situation is aggravated by the fact that the dam base lays on the recent and ancient meanders of the Arabel River. Here the underflow, recharged by infiltration of the tailings water, is preserved, in spite of the diversion of the stream flow to the artificial channel beyond the TSF. Geophysical investigations revealed a system of tabetisol areas (Figure 2a) formed by these meanders at the dam site. In the course of its construction and operation, facility rehabilitation required high effort and additional financial costs to stabilize the dam by the construction of a shear key. At the same time new questions arose, concerning the redistribution of seepage flows in the base and body of the dam, as the soil of the shear key freezes.

Thus, insufficiently detailed engineering and geological study of the dam soil foundation, especially changes in the physical and mechanical properties of all the lithological varieties in the section at the boundary cryogenic condition, did not allow geologists, engineers and project leaders to precisely calculate and predict the stability of the object, even in the short term. This is an illustrative example of how important it is to study the internal fine structure of the rock mass in high mountain conditions at the base of engineering structure foundation and the properties of each structural element despite its insignificant thickness compared to the size of the constructed projects.
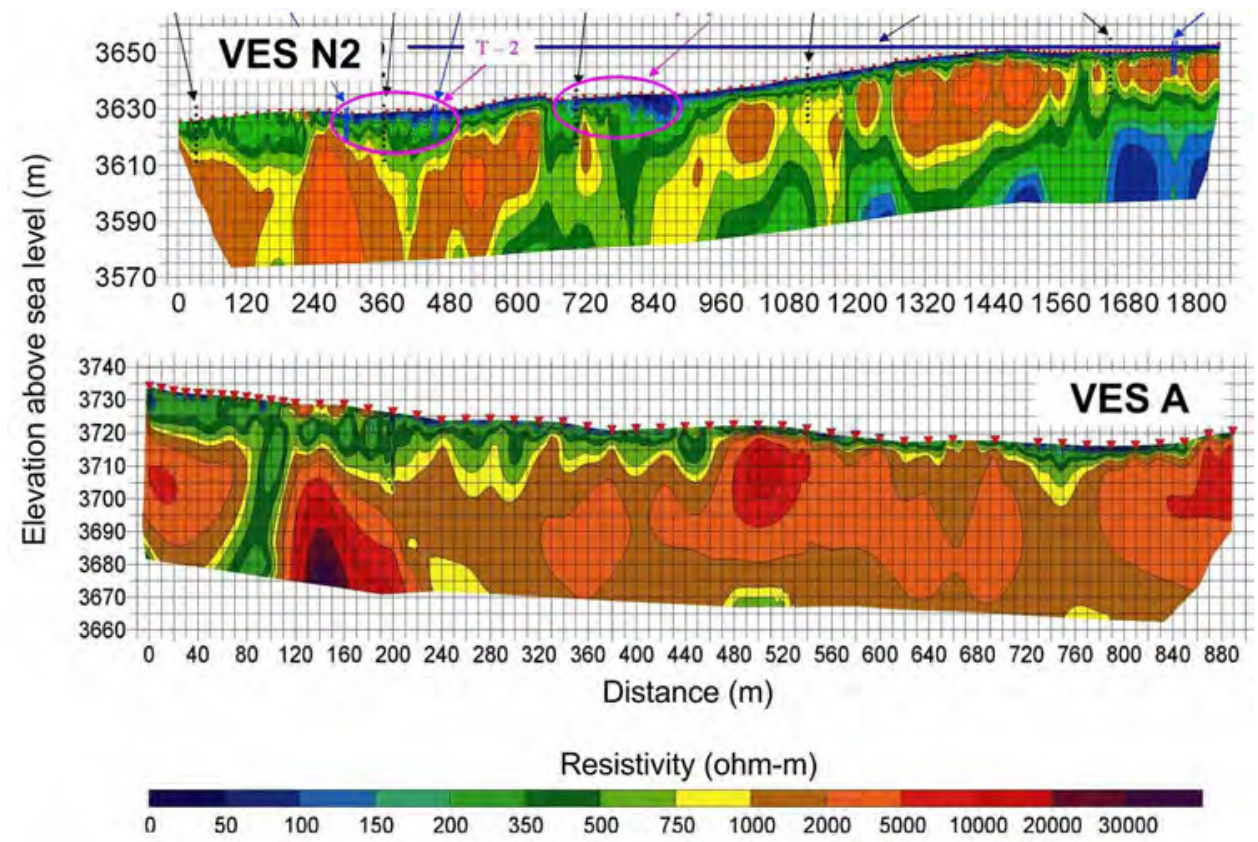

Fig. 2. 2D geoelectrical images of the subsurface along (a) the tailings dam and (b) Arabel River diversion ditch. 
The activation of the second group of risk factors is associated with climate change and man-made impact on the large catchment area, which exceeds the tailings area by 55 times. Reserves of moisture in the grounds of this area, including buried ice, may exceed 1 billion $\mathrm{m}^{3}$, and the water temperature in small lakes reaches $13{ }^{\circ} \mathrm{C}$ in summer. Permafrost degradation and development of thermokarst lead to deformations of the diversion ditches that divert the Arabel River, creating conditions for uncontrolled sudden runoff of surface and ground water into the tailings pond. The roofing of frozen rocks along the banks of the diversion ditches is already largely cut up (Figure 2b). Here, deep watered taliks are revealed, acting as reservoirs, collecting and transporting the suprapermafrost water toward the tailings pond. For long-term perspectives after the completion of mining operations, it is now necessary to assess the risks associated with watering the burial material and flooding the entire area abandoned tailings.

Factors of the third group form the danger of Petrov Lake moraine dam breaching (Figure 3), followed by the formation of a heavy debris flood, of which the solid phase will contain large blocks of buried glacier ice [3]. In [4] we discussed various reasons and scenarios for the development of such catastrophic process. During the spreading of debris flow along the outwash plain and the Kumtor River, a stream blockage in a narrow part of the valley and the overflow through a low lateral moraine into the tailings pond, followed by the destruction of the tailings dam and the release of cyanide-containing waste substances into the environment is not unlikely. It should be noted that the small difference in altitude (approximately $10 \mathrm{~m}$ ) between the Kumtor valley bottom and the lateral moraine that surrounds the tailing pond can be eliminated when removing debris from the Lysii Glacier or in time by the degradation of the moraine itself through buried glacier ice melting. Judging by the special "pockmarked" relief of its surface, these processes are already actively occurring.

The impact of these groups of risk factors is distributed in time as follows:

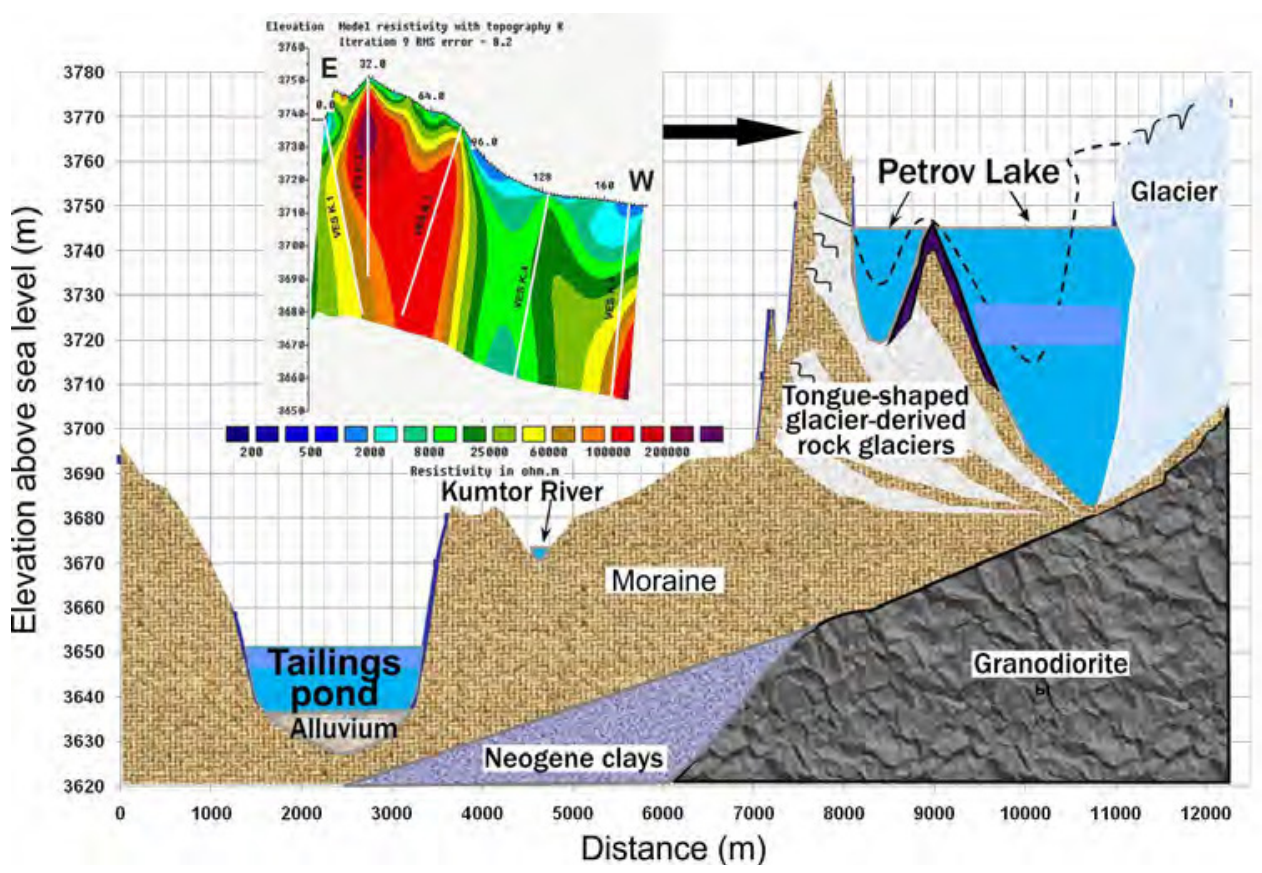

Fig. 3. Schematic geological cross-section in the area of formation of the debris flow and flood hazard in case of Lake Petrov dam breaching. The inset shows the geoelectrical image of the dam cross section. 
- The first group - from the beginning of the construction and operation of the TSF with an increased risk of destruction of the facility during the use of the initial project and its gradual reduction as monitoring data are received, engineering-geological knowledge, rehabilitation and adjustment of the project;

- The second group - from the moment of completion of mining operations, conservation of the facility and mine abandonment with increasing risk in time, consistent with changing climatic conditions;

- The third group - from the beginning of construction and operation of the facility with a constant increase in the risk of destruction of the object in time, in accordance to the change of climatic conditions.

At the moment, the knowledge of the second and third groups of risk factors is clearly insufficient to obtain specific numerical estimates of the destruction risk for tailings. It is necessary to carry out detailed geological investigations while the mine is still operating and it is possible to take adequate measures to ensure the safety of the TSF. These investigations must be accompanied by necessary calculations confirming the regulatory safety of TSF and, on the other hand, requiring special and additional technological measures to ensure the implementation of such standards, with the aim to obtain new information.

\section{Example of risk assessment of factors in the first group}

An example of a rapid and effective response of the mining company to the impact of the first group of risk factors is a set of measures aiming to stabilize the tailings dam, including: careful analysis of the monitoring data; installation of additional equipment to fix and localize the unstable sections of the dam and their displacement planes; further engineering, geological and geophysical surveys in dam body and downstream; the swift development of a stabilization project that provides for the removal of unstable clayey interbed behind its downstream slope to a depth of 10 meters, replacing it with rudaceous rocks, and finally, intensive implementation of the project. We took part in the implementation of some activities.

Immediately after the completion of the rehabilitation project, a risk analysis of the tailings dam failure (in fact, its updated version) was performed. Hazard analysis using monitoring data from 2011 made it possible to identify three main scenarios of tailings failure due to dam collapse:

B1. Dam collapse as a result of the development of seepage deformations in the soils of dam body and foundation.

B2. Dam erosion due to overtopping in case of additional water inflow into the tailings pond.

B3. Loss of stability of the downstream slope and/or entire dam as a result of a shear along the remaining loam interbed areas.

The most dangerous scenario is a hydrodynamic accident in the form of tailings release at the entire dam height in case of stability loss. The modeling of this type of failure was carried out using the "Tailings Flow Slide" code. The main results of the calculation are: the tailings run-out distance is 660 meters for a total time of 70 seconds with maximum flow rate $18.4 \mathrm{~m} / \mathrm{s}$. An accident of this scenario is classified as a local emergency situation related to the threat to the lives of up to 10 people. The quantitative risk analysis and development of safety measures are recommended for such cases [5].

The Fault Tree Analysis (FTA) method was used to quantify the risk of failure in case of dam stability loss. Figure 4 shows the "fault tree" for scenario B3 with its elements.

Taking into account the durability of the dam, the average annual probability of a dam failure under static conditions is $R_{s}=1.76 \times 10^{-4}$ year $^{-1}$; under seismic load $R_{c}=3.83 \times 10^{-4}$ 


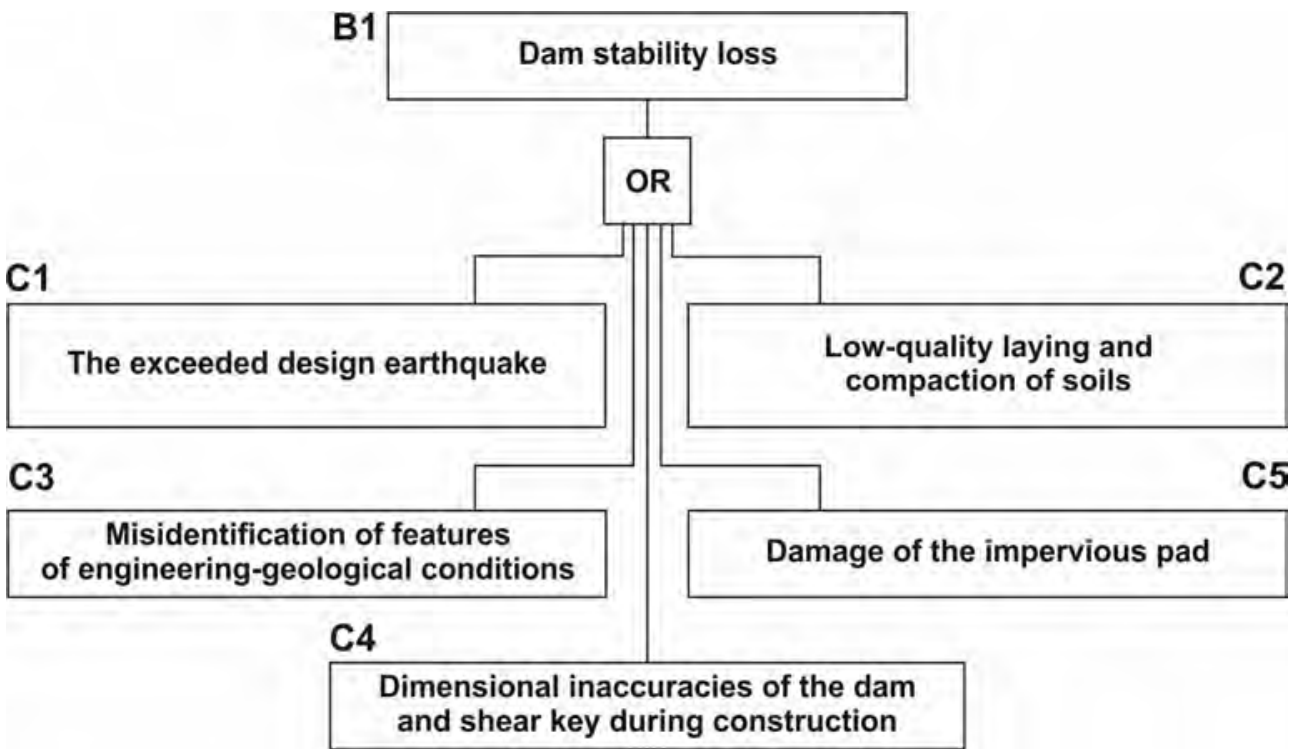

Fig. 4. Fault tree for scenario B3

year $^{-1}$. The regulatory risk for earth dam of Class 2 is $5 \times 10^{-4}$ year $^{-1}$ during the operation period.

The comparison of the calculated values with the normative value of risk makes it possible to consider the risk of an accident at the Kumtor TSF during operation in 2012 under static and seismic conditions as acceptable.

\section{Conclusion}

Taking into account the extremely high geomorphological, seismotectonic and geocryological mobility of the Tien Shan mountain-folded terrain, it is possible to support the thesis $[5,6]$ on the inadmissibility of using the same data obtained in the early stages or stages of the design or construction of the facility and/or on a nearby site, to assess its current safety, especially for a forecast with any time horizon.

The construction of large-scale and environmentally hazardous facilities in poorly studied high-altitude areas should be based on detailed monitoring of the facility itself and the environment. If necessary, prompt adjustment of the projects and urgent rehabilitation of the newly constructed facility should be established. It is necessary to be prepared for its early close-out, the search for new sites and the relatively high additional costs associated with all these activities. The design and maintenance of objects in a safe way under such conditions have, in fact, a cyclical or permanent character, based on newly obtained engineering, geological and geo-ecological data, as well as on the analysis of the manifested "defects", weakened zones, unstable sites in the interaction of objects with geological medium.

\section{References}

1. Yu.G. Aleshin, I.A. Torgoev, Sergeev's Readings. Engineering geology: state-of-theart and future prospects. 6. 322-326 (Moscow, 2004) 
2. G.N. Falaleev, Stress state of the rock massif and induced geodynamics of subsoil. 278-284 (Bishkek, 2006)

3. Yu.G. Aleshin, I.A. Torgoev, G.E. Ashirov, K.A. Abirov, Reducing the risk of natural disasters in mountains. 19-22 (Bishkek, 2009)

4. I.A. Torgoev, Yu.G. Aleshin, Geoecology and Wastes of Mining Complex in Kyrgyzstan, 239 (Bishkek, 2009)

5. I.T. Aitmatov, Yu.G. Aleshin, I.A. Torgoev, Izvestiya NAS KR. 1. $53-63$ (Bishkek, 2011)

6. N.P. Laverov, V.I. Velichkin, B.T. Kochkin, V.I. Malkovsky, V.A. Petrov, A.A. Pek, Geoecology. 3. 195-206 (2010) 